Disclosure of Interests: Jens Ole Rasmussen: None declared, Willy Fick: None declared, Jette Primdahl Speakers bureau: BMS and Pfizer, Ann Bremander: None declared

DOI: 10.1136/annrheumdis-2020-eular.2917

\section{THU0575 \\ THE EFFECT OF PREOPERATIVE PHYSICAL ACTIVITY ON KNEE AND HIP ARTHROPLASTY OUTCOME IN PATIENTS WITH OSTEOARTHRITIS}

E. Vandelli ${ }^{1}$, C. Duflos ${ }^{2}$, S. Akouete ${ }^{2}$, F. Guillemin ${ }^{3}$, A. C. Rat ${ }^{4}$, Y. M. Pers ${ }^{5}$ on behalf of the KHOALA Cohort Study. ${ }^{1}$ University Hospital of Montpellier, Clinical Immunology and Osteoarticular Diseases Therapeutic Unit, Montpellier, France; ${ }^{2}$ University Hospital of Montpellier, Clinical Research and Epidemiolgy Unit, Montpellier, France; ${ }^{3} \mathrm{CHRU}$ Nancy, Inserm, Université de Lorraine, CIC 1433 Clinical Epidemiology, Vandoeuvre-les-Nancy, France; ${ }^{4}$ Université de Caen Normandie, Université de Lorraine, CHU Caen, Caen, France; ${ }^{5}$ RMB, University of Montpellier, Inserm U1183, Montpellier, France

Background: Joint replacement is a therapeutic option increasingly widespread among osteoarthritis (OA) patients. Besides improving operating techniques and postoperative management, it is important to pursue the best preoperative conditions in order to achieve the desired result. As physical activity (PA) potentially acts on the preoperative predictors, knowing the effect of leisure and occupational PA should be of great interest to obtain a positive outcome.

Objectives: To investigate the influence of preoperative PA on the clinical outcomes of total hip arthroplasty (THA) and total knee arthroplasty (TKA) in OA patients.

Methods: Data from the Knee and Hip OsteoArthritis Long-term Assessment (KHOALA) cohort (1), a multi-regional French cohort of 878 patients with symptomatic hip and/or knee OA, were analysed. We included in our study patients undergoing THA or TKA during a 7-year-follow-up period. The level of total and leisure-time preoperative PA was measured with the Modifiable Activity Questionnaire (MAQ). Outcomes were measured one year after surgery. For the primary endpoint, quality of life (QoL) was measured with the OsteoArthritis Knee and Hip Quality Of Life questionnaire (OAKHQOL). For secondary endpoints, QoL was measured with Short Form 36 (SF-36), pain with the Visual Analogue Scale (VAS), function with the Western Ontario and McMaster Universities Osteoarthritis Index (WOMAC) and with walking distance. The population characteristics were described using frequency or mean and standard deviation (SD), depending on the distribution of the variable. Association between exposures and outcomes was calculated with a multivariate linear analysis with backward selection, adjusting for confounders (age, sex, body mass index, site of joint replacement, polyarticular OA, OA duration, comorbidities, radiological grade of $\mathrm{OA}$, inclusion centre, rehabilitation after surgery, previous joint issues, instruction level). A p-value $<0.05$ was set as statistically significant.

Results: 150 patients were included. 58.7\% underwent TKA and $41.3 \%$ THA. The mean age at the time of surgery was 66.6 years $( \pm 7.7 \mathrm{SD})$. The majority of patients were female $(75 \%)$, overweight (mean BMI $29.63 \mathrm{~kg} / \mathrm{m} 2, \pm 5.5 \mathrm{SD}$ ) and had polyarticular OA $(60 \%) .53 \%$ of patients met the World Health Organization recommendations on PA before surgery. For the primary endpoint, a high preoperative total PA was associated with a better relationship with the partner ( $\beta=0.55, p=0.02$ ) one year after surgery. As for secondary endpoints, a high two-year preoperative total PA was associated with an impaired SF-36 Mental Component Summary score $(\beta=-0.87, p=0.02)$, but a longer walking distance $(\beta=442.81, p<0.01)$. Leisure-time PA also showed a positive impact on walking distance $(\beta=76.25, p=0.02)$, but a negative one on social functioning in SF-36 $(\beta=-0.47, p=0.01)$. No statistically significant association between preoperative $\mathrm{PA}$ and pain nor WOMAC was found.

Conclusion: In this cohort study, the preoperative level of PA demonstrated a heterogeneous effect on the various aspects of QoL one year after THA and TKA in OA patients. Preoperative PA was directly associated with gain of function, measured as walking distance, after surgery. Considering the increasing prevalence of OA and the crucial role of PA on health, further studies on this relevant topic are needed.

References:

[1] Guillemin F, Rat A-C, Roux CH, Fautrel B, Mazieres B, Chevalier X, et al. The

KHOALA cohort of knee and hip osteoarthritis in France. Joint Bone Spine. 2012 Dec 1;79(6):597-603.

Disclosure of Interests: Enrica Vandelli: None declared, Claire Duflos: None declared, Sandrine Akouete: None declared, Francis Guillemin Grant/research support from: Francis Guillemin received a grant from Expanscience paid to his institution., Anne-Christine Rat: None declared, Yves-Marie Pers: None declared

DOI: 10.1136/annrheumdis-2020-eular.2040
THURSDAY, 04 JUNE 2020

\section{Education}

THU0576

EMPOWERING PEOPLE WITH RHEUMATIC AND MUSCULOSKELETAL DISEASES TO BE AT THE HEART OF MEDICAL EDUCATION: A EULAR SCHOOL OF RHEUMATOLOGY INITIATIVE

S. Grealis ${ }^{1}$, A. Alunno ${ }^{2}$, M. Bernardy ${ }^{3}$, V. Romero Pazos ${ }^{4}$, T. P. M. Vliet Vlieland ${ }^{5}$, C. Haines ${ }^{6}$, D. Wiek ${ }^{3} .{ }^{1}$ Arthritis Ireland, Dublin, Ireland; ${ }^{2}$ Rheumatology Unit, Perugia, Italy; ${ }^{3}$ Deutsche Rheuma Liga, Bonn, Germany; ${ }^{4}$ LiRE, Madrid, Spain; ${ }^{5}$ LUMC, Leiden, Netherlands; ${ }^{6}$ King's College, London, United Kingdom

Background: The earliest examples of active patient involvement in teaching are interventions in which the patient was teaching students how to conduct physical examinations. Over the last two decades, educators have used the expertise of patients to enrich the education of undergraduate physicians and health professionals (HP) in several ways, mainly asking people to outline their own stories. Early patient involvement also aims to sensitise students to pursue a holistic approach and ultimately to build a trustful physician-patient relationship. Most studies report that high patient involvement brings benefits to both learners and patients. Learners report higher satisfaction. Patients report raised self-esteem and empowerment, new insights into their problems and deeper understanding of the physician-patient relationship.

Objectives: To develop a novel educational framework within the EULAR School of Rheumatology for people with rheumatic and musculoskeletal diseases (RMDs) who are willing to be involved in teaching undergraduate physicians and HPs (Patient Education Partners, PEPs).

Methods: A multidisciplinary working group including people with RMDs, 1 Rheumatologist, $1 \mathrm{HP}$ in rheumatology and 1 educationalist was established. The project was developed through a questionnaire launched in May 2019, to patient associations across Europe, 2 face to face meetings and online teleconferences. Results: Patient associations from 23 European countries responded to the questionnaire and in 10 of them (43\%), there have been programmes running for up to 31 years which involve patients with RMDs in undergraduate education. To some extent, 485 people with RMDs have been trained over the years across Europe. However, there are different country and disease-specific types of training and a lack of standardised training for patients involved in these programs. The patient associations from countries that do not have the programme would be interested in taking part, if such initiative were to be developed. The topics that people would like to cover when teaching medical and other health professions students are: disease specific factors, doctor-patient communication, personal history and physical examination, the importance of education and work to the individual, the impor tance of disease self-management. A subsequent mapping of European countries was undertaken to identify best practice examples of existing programmes: Germany, Denmark, Belgium, Ireland and the UK were included. From these foundations, we developed a new on-line Course, to equip patients with a basic medical knowledge about their disease and effective communication strategies.

Conclusion: We established a European framework to train people with RMDs who were willing to be involved in teaching undergraduate physicians and HPs. This will allow them to gain confidence and effective communication skills to share their lived experience and become PEPs. The content of the course is currently being developed and all EULAR pillars are involved. Participation in this training course, particularly by people from countries that do not yet engage patients in undergraduate education, may facilitate the implementation of such initiatives, and ultimately improve the training of physicians and HPs across Europe.

References:

[1] Wykurz G et al. BMJ 2002;325:818

[2] Walters K et al. BMJ 2003;326:740

Disclosure of Interests: None declared

DOI: 10.1136/annrheumdis-2020-eular.4578

\section{THU0577 INFLUENCE OF THE ROUTE OF ADMINISTRATION ON SAFETY AND ADHERENCE PRACTICES OF RHEUMATOID PATIENTS TREATED BY JAK-INHIBITORS AND OTHER DMARDS. AN ETHNOGRAPHIC STUDY FOR AN APP-BASED EDUCATIONTOOL.}

G. Montagu ${ }^{1}$, S. Gleizes ${ }^{2}$, T. Pham ${ }^{3}$, J. Sellam ${ }^{4}$, C. Beauvais ${ }^{5} .{ }^{1}$ Unknowns, Strategic and Innovation Consulting, Sociology and Research Department, Paris, France; ${ }^{2}$ Unknowns, Strategic and Innovation Consulting, Sociology and Research Department, Paris, France; ${ }^{3}$ Hopital Sainte-Marguerite, AP-HM, AixMarseille Université, Rheumatology Department, Marseille, France; ${ }^{4}$ Hopital Saint-Antoine, AP-HP, Sorbonne University, Rheumatology Department, Paris, France; ${ }^{5}$ Hopital Saint-Antoine, AP-HP, Sorbonne University, Rheumatology Department, Paris, France 